\title{
The problem of distinguishing multiplicative from additive reasoning in primary school classroom context
}

\author{
Odd Tore Kaufmann \\ Department of teacher education, Østfold University College, Halden, Norway \\ For correspondence: odd.t.kaufmann@hiof.no
}

\begin{abstract}
This article investigates how students in third grade learn to reason on multiplication when they first encounter that concept in the classroom context. By analysing the data from 24 classrooms focused on teaching and learning multiplication, the article aims at contributing to the research and conceptualisations about how students learn to distinguish multiplicative from additive reasoning in a primary school. A central feature is the strong emphasis students have on addition when they work with multiplication. This emphasis on addition causes tensions in the discussions between the teacher and students. Results are discussed in relation to previous studies of students' multiplicative reasoning and implications for practice are elaborated upon.
\end{abstract}

Keywords: multiplication, repeated addition, reasoning, classroom study

\section{Introduction}

There is a need in education research to identify and build upon earlier studies as a way to confirm and extend knowledge in the field. Unfortunately in mathematics education, the lack of accumulation of such studies is one of the reasons why it has had relatively weak impact on practice and policy (Lesh \& Sriraman, 2010). According to Lesh and Sriraman, "[The] lack of accumulation is an important issue because most realistically complex problems will only be solved using coordinated sequences of studies, drawing on multiple practical and theoretical perspectives" (2010, p. 139). This study aims at accumulating knowledge by re-examining theories of students' development from additive to multiplicative reasoning, by studying how this passage manifests in primary school classroom context. Most of the studies on students learning multiplication are exemplary of the cognitive/rationalist approach based on experiments or interviews with individual students (e.g. Clark \& Kamii, 1996; Sherin \& Fuson, 2005; Van Dooren, De Bock \& Verschaffel, 2010), with little attention to the broader cultural or instructional contexts in which these studies take place (Verschaffel, Greer, \& DeCorte, 2007). To a large extent, the acquisition of multiplicative reasoning builds on students' additive reasoning capacities since multiplication often can be conceived as a repeated addition (Fernández, Llinares, Van Dooren, De Brock \& Verschaffel, 2012). But there are also specific aspects that are not reducible to additive models such as "the Cartesian product" or the meaning of ratio and rate. As shown in previous research, a characteristic of the transition from additive to multiplicative reasoning is students' difficulty to discriminate multiplicative from additive situations, especially in tasks constructed as word problems (e.g. Van Dooren et al., 2010). However, how students learn to distinguish multiplicative from additive reasoning in a primary school setting by studying the classroom interaction working with that theme, is examined in few, if any, studies (Kaufmann, 2010). Theoretically the research takes its point of departure in a sociocultural perspective (Vygotsky, 1978), to study students' reasoning in multiplication. By using and analysing the data from 24 classroom lessons from eight third-grade classes focused on teaching and learning 
multiplication, the aim is at contributing to the research and conceptualisations of students' development from additive to multiplicative reasoning. The research question guiding the article is: What are the tensions in the transition from additive to multiplicative reasoning in primary school classroom context?

How students reason about addition and multiplication is affected by how they are used to reason about mathematics in a classroom situation. In a broader context, and from a Nordic perspective, there have been several important empirical studies on classroom interaction and the role of students' contributions in mathematical whole-class discourse (Emanuelsson \& Sahlström, 2008; Ryve, Larsson, \& Nilsson, 2013; Streitlien, 2009). The results of this study will add to this discussion of how teachers and students act in whole-class discourses within the Scandinavian context.

\section{From additive to multiplicative reasoning}

In a Nordic context, multiplication is typically introduced by repeated addition (Larsson, 2016; Kaufmann, 2010), which can be regarded as a natural way to introduce multiplication in school (Fischbein, Deir, Nello \& Marino, 1985). There are connections between addition and multiplication, but there are also some decisive differences. One differences between addition and multiplication is the quantities that are involved. If we add three books with five books, the quantity (books) are still the same. In multiplication, there is more than one quantity involved. If three children has five books each, they have 15 books together. The quantity change from children and books to books. Addition is referent preserving while multiplication is referent transforming (Schwartz, 1988). Another difference is that while addition deals with single units, multiplication deals with composite units (Clark \& Kamii, 1996). To add $5+5+5$, additive thinking involves inclusion relations on only one level; the groups are combined successively as five plus five etc. In contrast, multiplication involves a one to many correspondence; one student has five books. In order to keep the correspondence one student with five books constant, each time we add one student to the set of students we must add five books to the set of books - that is, we add different numbers of objects to each set. This contrast with the additive situation where, in order to keep the difference between two sets constant, we add the same number of objects to each set. Further, a conception of multiplication as repeated addition can be problematic for the students when multiplication is applied to decimals (Verschaffel, Greer \& DeCorte, 2007), Cartesian product (Mulligan, 1992) or proportionality (Tzur et al, 2013). On the other way, in the initial learning of multiplication, students often start by counting all objects, and move from repeated addition to multiplicative calculations (Sherin \& Fuson, 2005; Mulligan \& Mitchelmore, 1997).

Research (Fischbein et al., 1985; Mulligan \& Mitchelmore, 1997) has identified a number of intuitive models constituting and affecting students' reasoning. The discussion of intuitive models can be traced back to an article by Fischbein and colleagues (1985). In this article they hypothesize that "Each fundamental operation of arithmetic generally remains linked to an implicit, unconscious, and primitive intuitive model (Fischbein, et. al (1985), p. 4). They asked 623 students in Italian Schools at grades 5, 7 and 9 to choose the operation needed to solve twelve multiplication word problems. These word problems contained factors with whole number, factors with a whole number and decimal number, and factors with decimal numbers. Fischbein et. al (1985) found that the role of the decimal in the structure of a multiplication problem is clearly decisive in retrieving the correct operation, and concluded that a primitive model of multiplication is repeated addition. Mulligan and Mitchelmore (1997) interviewed 60 girls in two successive years when the students were in grade 2 (and had received teacher instruction in basic addition and subtraction but not in multiplication) and in grade 3 (when they were given instruction in basic multiplication), as they solved the same set of word problems based on Greers (1992) categories. From the correct responses during these interviews, it was found that the students used three main intuitive models. Direct counting by using either cubes 
or visualization and then counting the cubes one by one. Repeated addition by rhythmic counting (e.g. 4 × 3: "1, 2, 3, 4, 5, 6, 7, 8, 9, 10,11, 12, simultaneously with counting, a second count is kept of the number of the groups), skip counting (e.g. $4 \times 3$ : “3, 6, 9, 12," counting is done in multiples), or additive calculation that take advantage of the equal-sized groups present in the word problem (e.g. 4 x 3: counting is replaced by calculation such as $\left.3+3=6,6+3=9,9+3=12,{ }^{\prime \prime}\right)$. At last multiplicative operation, a model that was inferred when students gave correct responses without appearing to form the entire sequence of multiples.

Research on United States prospective teachers' knowledge of multiplication identified that many hold a primitive model of multiplication as repeated addition, which leads to their difficulty in making sense of an operator that is not a whole number (Lo et al., 2008). If these becoming teachers lacks a well-developed concept of multiplication, it will affect the way they treat the concept of multiplication in their classrooms. Sherin and Fuson (2005) argue that in any learning progression in multiplication strategy use will depend on the nature of instruction. It has been shown that students use diverse of strategies throughout their learning period (Lefevre et al., 1996), and Anghileri (1989) found a variety of strategies including; unitary counting with grouping, adding, using a number pattern, doubling etc.

Greer (1992) claims that the most important classes of situations involving multiplication of integers include equal groups (e.g. four children have three balloons each. How many balloons are there altogether?), multiplicative comparison (e.g. Lisa has three times as many pencils as Carl has. Carl has four pencils. How many pencils does Lisa have?), Cartesian product (e.g. Dina has three types of pants and four types of sweaters. How many different outfits can she choose?) and rectangular area (What is the area of a rectangle when the lengths of its sides are 4 and 3 centimetres?). Based on students' success rates of solving word problems, a number of studies have demonstrated that equal groups and rectangular array and area problems are easier than multiplicative comparison and hardest are Cartesian product (Greer, 1992; Mulligan, 1992). The prevalent explanation in the literature to larger success rates for some models is the frequent occurrence of these types of problems in instruction (Verschaffel et al., 2007); equal groups problems are frequent in primary school and a common model in the introduction of multiplication (Fischbein et al., 1985). English and Halford (1995) argue that the common practice of using a repeated addition approach to interpret multiplicative situations reflects a fundamental misunderstanding of its role. That is, it appears that repeated addition is used both as a representation of the problem situation as well as the corresponding mathematical model. Multiplicative comparison of two quantities involves ratio, which might explain the slow process of transition to multiplicative reasoning (Larsson, 2016). In order to develop a robust ability to reason multiplicatively, the students must be able to distinguish when multiplicative reasoning is appropriate and when not (Clark \& Kamii, 1996; Van Dooren et al., 2010).

This literature review has described multiplicative reasoning as ability to coordinate composite numbers at several levels of abstraction and researchers have investigated students' multiplicative reasoning by their calculations (Tzur et al., 2013). Others have tested students' ability to reason multiplicatively by their ability to interpret proportional or multiplicative comparison problems (Clark \& Kamii, 1996; Van Dooren, De Bock, \& Verschaffel, 2010).

Based on this literature review there seems to be obstacles in considering repeated addition as multiplicative reasoning, and it might be that repeated addition approach is as a an undesirable approach in the transition from additive to multiplicative reasoning. The contribution of this research is to describe the difficulties in the transition from additive to multiplicative reasoning in primary school classroom context. 


\section{Method}

This study is conducted within an interpretive research paradigm (Carr \& Kemmis, 1986). The aim is to understand and interpret how students encounter and reason about multiplication in a primary school classroom. Reasoning in the classroom is seen as a process of students' appropriation of multiplication. The use of discussion as a tool to increase reasoning has gained emphasis in classrooms worldwide and in Norwegian classrooms (Ludvigsen et al., 2016). A central part of the teaching in mathematics at primary school in Norwegian classroom are based on teacher discussing with the student about the tasks and their solutions (Streitlien, 2009). In these situations the teachers often asks, after received a solution from a student, how she or he have thought when they solved the task. To study how students reason about multiplication in school, it is appropriate to follow the discussion about multiplication from the participants in the classroom.

The students encounter multiplication in 3rd grade in Norway. The time working with multiplication is quite dense, and the period of multiplication last about three to four weeks during that specific school year. This study is about students first encountering with multiplication in primary school, and the data material is collected from the three first consecutive lessons. Therefore, this study could be regarded as focused ethnography (Knoblauch, 2006). As opposed to conventional ethnography with long-term field visits, this this study rely on an approach where you have a short-time visit. The short time period is compensated for another type of intensity; data intensive. Focused ethnographies produce a large amount of data in a relatively short time period. To collect data that are helpful for studying the reasoning on multiplication, three consecutive, introductory multiplication lessons were video and audio recorded in eight classrooms. The video camera was located in the back of the classroom for a better view of both the teacher and the students. An audio recorder was attached to the teacher just in case if the sound from the video recorder was unclear. The video recordings are done in classrooms and are naturalistic in the sense that students are in their everyday environment engaging with mathematical activities. Focused ethnography and video analysis converge since they are both oriented to the conduct of people in their natural environment (Knoblauch, 2005).

Overall, seven teachers from five schools participated in this project. One of the teachers also taught mathematics to two different groups in the third grade, and both groups were involved in the project. The total video recording time in each class varied from 98 to 224 minutes, with an average of 156 minutes per class. All the teachers were women in age between 45 and 63 . They are experienced teachers, with between 12 and 35 years of teaching experience. Five of the teachers have graduated from teacher education. The two others have graduated from kindergarten education, with postqualifying education to teach at level one to four.

\section{Data analysis}

From a sociocultural perspective, the classroom practices are not regarded as a window to capture individuals' cognitive processes; instead, these practices should be viewed as a process of participation in classroom activities. Therefore, a suitable unit of analysis to capture the reasoning processes constitutes the interactions (or rather, subsections of interactions) occurring when students are working on multiplication, based on conversations about solution strategies. These interactions include the dialogues among the participants, the activities they perform and the discussions about the tools they use in these activities. The data analysis therefore involves the discussion of the teacher and her students working on multiplication in class. The specific interest here is to explore students' tensions in the transition from additive to multiplicative reasoning when they are working with multiplication in the classroom. Theoretically the research takes its point of departure in a sociocultural perspective (Vygotsky, 1978), to study students' reasoning in multiplication. Words and linguistic expression, among others cultural tools, makes it possible for the participants in the 
classroom to communicate and build their knowledge on each other. The conversation is therefore the most important arena for learning (Säljö, 2005). When students learn to handle concepts used in multiplication, they learn both how to reason and how this conceptual content are determined within a particular practice, such as the school. From a sociocultural perspective learning is viewed as how individuals appropriate knowledge and skills they are exposed, "taking what someone else produces during [a] joint activity for one's own use in [a] subsequent productive activity while using new meanings for words, new perspectives, and new goals and actions" (Moschkovich, 2004, p. 51). The direction taken by appropriation (Säljö, 2005; Wertsch, 1998) is neither linear nor easy; it includes a tension between the tool (developed and understood in a broader culture) and how it is utilised in a particular context. An important and fascinating aspect of appropriation is that when a person acquires and uses a new tool, it always involves a conceptual tension or even resistance (Wertsch, 1998). A tool offers a meaning that has to be adapted to a specific case or a concrete problem. How the cultural tool is to be used is often not a decided and fixed matter, especially in the case of the user who is not accustomed to it. The participants in the classroom often alternate between the strategies in multiplication at a quick speed; sometimes, they connect these together, while at other times, they focus on the differences. In this classroom context, mastery of multiplication means the process of change in which students adopt their language as it functions in multiplication and how they manage to utilise the physical tools in the classroom. In this appropriation process, it turns out that students face a certain tension in the tools being used. Although students master the learned product in multiplication, they must also interpret the activities and use the tools in a multiplicative context.

All the video recordings was transcribed and analysed in order to study how students learn to reason about multiplication. These transcriptions contained all the verbalization between the participants in the classroom, most often between the teacher and the students but also between students when they were working in groups, (we chose to follow one of the groups in the classroom in such situations). Pictures from the video camera was also attached to the transcriptions in these cases were the pictures could clarify the situation. For instance, when the participants are discussing a mathematical task written on the board, a picture of the board could be clarifying. Then we studied the video recordings several times. Video analysis can be regarded as akin to forms of analysis, which are based on sequentiality, i.e. actions and interactions, such as conversation analysis (Bryman, 2012). By looking at the video material and reading the verbalizations of the transcripts, we first identified episodes and categorized them due to a taxonomy based on Kaufmann (2010) and Sherin and Fuson (2005); strategies students use in primary school solving single-digit multiplication. Studying how teacher and students discussed these strategies in the classroom, we found several situations when the participants did not agreed and often could not solve these disagreements during the discussion, and tensions arise. This were found in conversations focusing on for instance counting all object, skip counting or the commutative law in multiplication. After grouping the tensions according the taxonomy, we found definitely most tensions when the students tried to connect repeated addition to multiplication, and therefor started to mark all the situations in the transcription where we could find tension in students reasoning in multiplication, the students explain, clarify or reason about the relation between addition and multiplication. Then the data was categorized, a category creation (Alvesson \& Sköldberg, 2009) that could explain the tension in the classroom discussions. Analysing students tensions in the transition from additive to multiplicative reasoning, two categories was formed and these are presented in the next chapter.

\section{Results}

Much of the classroom activity in primary school is performed orally through discussions about tasks and their solutions, either between the teacher and the students or among the students. When student discuss and reason about their solution methods in primary school classrooms, some of the features within previous research are helpful in characterizing the students' reasoning about multiplication. 
These includes students reasoning on multiplication using count-all, count-by, repeated addition, pattern based and learned product strategies. In this section, we will present some of the challenges students face in the classroom working with multiplication at an early stage. These challenges can be separated in two main categories. One is the tension in the discussion, often between the teacher and student that arise when the students solutions are based on addition or repeated addition that are different from the teacher's expectation. Another challenge how the tools used in the classroom are too close to the students' previous experiences with similar tools used in addition, which leads the students' attention away from the multiplicative problem.

\section{From additive to multiplicative reasoning...or not!}

In studying the classroom discussions, it was very apparent that the students largely used addition or repeated addition when they explained how they solved multiplicative tasks. In these discussions about the solution strategies, it was also apparent that the teachers often struggled when they tried to guide the students reasoning towards multiplication. Excerpt 1 illustrates some of these difficulties. This section describes the students' first lesson on multiplication in Anita's class. They have until now worked without the textbook, and the activities have focused on the grouping of equal amounts. In this situation, the students and the teacher (Anita) are discussing a picture of a birthday party on the first page in the textbook's multiplication chapter, which shows five sodas with one straw in each. Anita asks questions related to this picture (figure 1).

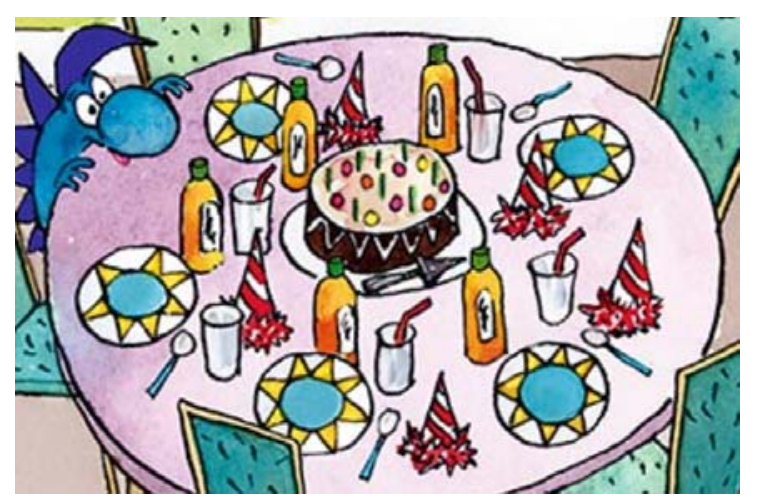

Figure 1

Excerpt 1. Additive calculation

\begin{tabular}{|c|c|c|c|c|}
\hline 225 & 25.09 & Anita & Yes (3) instead of one straw in each, we decide that & Originally, there \\
\hline 226 & & & there are two straws in each glass. How many & was one straw in \\
\hline 227 & & & straws will there be? (11). There are two straws in & each bottle, but \\
\hline 228 & & & each glass; how many straws do you have? (19). & Anita asks what the \\
\hline 229 & & & Ada? & answer will be with \\
\hline 230 & 25.53 & Ada & Ten. & two straws in each \\
\hline 231 & 25.54 & Anita & Yes. How did you solve that? & bottle. \\
\hline 232 & 25.56 & Ada & I count two four six eight. Eight ten. & \\
\hline 233 & 26.00 & Anita & Can you write that on the blackboard? & \\
\hline 234 & 26.10 & Ada & What should I write? & \\
\hline 235 & 26.11 & Anita & Hmm? & \\
\hline 236 & 26.12 & Ada & What should I write? Should I write two, four? & Ada writes $2+2+2$ \\
\hline 237 & 26.15 & Anita & Mmm, two and a plus between; can you write that? & $+2+2=10$ on the \\
\hline 238 & & & (38). Thank you (8). You, are there other ways of & blackboard. \\
\hline 239 & & & thinking? It is not finding the most difficult way. & \\
\hline 240 & & & Aksel? & \\
\hline 241 & 27.11 & Aksel & Five plus five. & Aksel writes $5+5$ \\
\hline
\end{tabular}




\begin{tabular}{|c|c|c|c|c|}
\hline 242 & 27.12 & Anita & Yes. & on the blackboard. \\
\hline 243 & & & [Oh, that was what I was going to say.] & \\
\hline 244 & 27.16 & Stud ${ }^{*}$ & But I know a different one. & \\
\hline 245 & & & {$[\mathrm{Me}$, too. $]$} & \\
\hline 246 & 27.19 & Anita & Do you? (17). Thanks. Atle? & \\
\hline 247 & 27.38 & Atle & One plus one plus one till I arrive at ten. & \\
\hline 248 & 27.42 & Anita & Mmm. Ari? & \\
\hline 249 & 27.43 & Ari & One plus one plus one plus one plus two plus two & \\
\hline 250 & & & plus one. & \\
\hline 251 & 27.46 & Anita & Arnt? & \\
\hline 252 & 27.48 & Arnt & Four plus six. & \\
\hline 253 & 27.50 & Anita & Mmm. Yes. & \\
\hline 254 & 27.54 & Stud & Ehh ohh ehh, three plus two, two plus three. & \\
\hline 255 & 27.59 & Anita & Heheh. & \\
\hline 256 & 28.00 & Stud & And so on. & \\
\hline 257 & 28.01 & Anita & Yes, but now you start to make (3) it more difficult & \\
\hline 258 & & & than it is, isn't it? & \\
\hline 259 & & & [Two plus three.] & \\
\hline 260 & & & Yes, now you are doing such difficult tasks. & \\
\hline 261 & 28.10 & Arild & I know a simple one. & \\
\hline 262 & 28.11 & Anita & Arild? & \\
\hline 263 & 28.12 & Arild & Eight plus two. & In this sequence, a \\
\hline 264 & 28.13 & Anita & Yes, but now- & lot of students are \\
\hline 265 & 28.15 & Stud & And nine plus one. & speaking in chorus. \\
\hline 266 & 28.16 & Anita & But that does not - & \\
\hline 267 & & Stud & [Yes, that was easy.] & \\
\hline $\begin{array}{l}268 \\
269\end{array}$ & 28.18 & Anita & Eight plus two is like Ada's [answer]. & Anita refers to \\
\hline 269 & & Stud & [Ten plus zero.] & another context in \\
\hline 270 & 28.20 & Anita & Then you have first added two and two becomes & the picture. \\
\hline 271 & & & four, plus two is six, plus two is eight, plus two is & \\
\hline 272 & & & ten ... But listen. All together, all the children. They & \\
\hline 273 & & & have clothes. & \\
\hline
\end{tabular}

(*When several students talk at the same time, it is difficult to find out who says what. These statements have therefore been attributed to "Stud" in the transcriptions.)

Anita moves away from the example related to the picture in the textbook, and asks how many straws there will be if there are two straws in each soda (227-229). Ada answers ten (230) and uses number counting as a strategy - two, four, six, eight, ten (232). This answer corresponds to the actual problem with two straws in five glasses. Anita asks for more suggestions (238-240). Instead of this discussion should take the direction from repeated addition to multiplication, Ari (249), Arnt (252) and another student (254) each suggest an addition with different group sizes. According to Sherin and Fuson (2005) and Mulligan and Mitchelmore (1997), in the initial learning of multiplication, repeated addition is thought of as an intermediate stage; students start by counting all objects, and move from repeated addition to multiplicative calculations. As we can see from the excerpt above this direction from repeated addition to multiplication is not straightforward. For these three students, it has become a game with numbers that provide the sum ten with various addends. The students' activities are situated in a school setting. Giving seemingly absurd responses related to multiplication, the meaning making practice the students engage in is not irrational. The students become used to "do school" through their own experiences, and through this socialization they appropriate (Moschkovich, 2004) the way that the discussion about different solutions to a task functions. Anita 
expected answers from the students related to multiplication and repeated addition (as illustrated in the two examples written on the blackboard) although some of the responses with repeated addition do not match the situation. To solve this tension (Säljö, 2005), Anita says that the students are suggesting difficult calculations (260). She does not focus on the one to many correspondence (Clark \& Kamii, 1996) between the glasses and the straws (one glass has two straws), but only on the total number of straws. Arild suggests eight plus two (263), and other students propose nine plus one (265) and ten plus zero (269). For these students, their suggestions mean easy calculations. Anita does not comment on a student's last reply (269) but offers feedback on Arild's answer of "eight plus two" and tries to link it (270-272) to Ada's response earlier. Without stating a conclusion, Anita proceeds to the next task (272-273).

Using additive calculation is quite common when students reason about multiplication (Fischbein et al., 1985; Mulligan \& Mitchelmore, 1996). On the other side, as shown in this excerpt, a problem that may arise is that some students may begin to use different sub-totals, which is quite common in addition. This means that the students deviate from using equal numbers. For example, instead of $6+$ 6 , a student may decide on $10+2$. However, such a strategy may prevent students from gaining an understanding of multiplication since it does not make sense in relation to multiplication. A common perspective is that because of students' prior learning experiences in addition, these existing resources can provide the basis for strategies that are less time-consuming and easier to enact than count-all strategies (Fischbein et al., 1985; Mulligan \& Mitchelmore, 1996). These strategies are based on addition-related techniques. It may be due to the students' previous experiences with addition since they have mastered this strategy. This way of using addition to arrive at the answer is meaningful for them. Repeated addition is considered more sophisticated than to count all, but it becomes a cumbersome strategy when the multi-digit multiplication is introduced (Larsson, 2016; Lo, Grant \& Flowers, 2008; Verschaffel et al., 2007). The excerpt above also show that repeated addition could become a cumbersome strategy as early as the introduction phase of learning multiplication in school, and this especially significant when most of the word problems students work with in primary school are word problems that include Greers (1992) category equal groups (Kaufmann, 2010). Teacher and student dialogues does not automatically lead to mathematically founded reasoning or deeper learning (Emanuelsson \& Sahlström, 2008). The meaning created in the relationship between addition and the glasses with straws is different for the teacher and the students. There is tension in the dialogue because the teacher's interpretation of the situation differs from those of the students.

\section{Use of familiar tools-earlier we added them.}

In the analysis from the class discussions another category became evident from the data; the problems that arise when using tools in multiplication. In several cases tensions (Säljö, 2005) emerged when the teachers and students used tools to exemplify the multiplicatice task. In several cases, some students had problems with this activity, and even after a lengthy discussion, they still had not obtained a shared meaning (Rogoff, 1990) with their teacher or classmates. The following example shows students master multiplication as a learned product but equally well struggle to understand the concept of multiplication in the specific situation. This situations starts with the teacher (Dorte) showing three pencils in two hands (figure 2) in front of the students and asking them to formulate a multiplicative task/solution. 

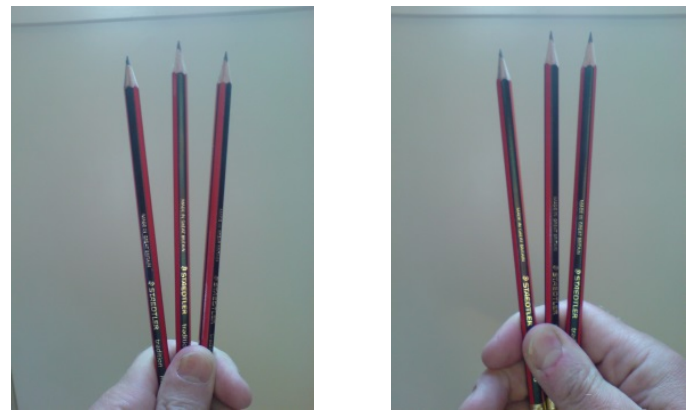

Figure 2

Excerpt 2. Students discuss the meaning of three pencils in two hands

\begin{tabular}{|c|c|c|c|c|}
\hline $\begin{array}{l}187 \\
188\end{array}$ & 19.42 & Dorte & $\begin{array}{l}\text { Do anyone have a multiplication task for me now.... } \\
\text { Denis }\end{array}$ & \\
\hline 189 & 19.49 & Denis & Eh I did not raise my hand & \\
\hline 190 & 19.51 & Dorte & No but I ask you even that you know. Derek and & \\
\hline 191 & & & Doris you should not talk now. Diana? & \\
\hline 192 & 20.00 & Diana & Six & \\
\hline 193 & 20.01 & Dorte & Yes, that is the answer. But how did you get it. What & Dorte \\
\hline 194 & & & do you call the multiplication task to get there? & points \\
\hline 195 & & & Denis. & three \\
\hline 196 & 20.08 & Denis & Ehh three plus three. & the \\
\hline 197 & 20.10 & Dorte & You can say that. If we should modify to & pencils \\
\hline 198 & 20.12 & & multiplication. What does it called then? & when the \\
\hline 199 & 20.20 & Denis & Ehh four... three times three & student \\
\hline 200 & 20.22 & Dorte & Three times how many hands had we again. & says four. \\
\hline 201 & 20.24 & Stud & Two & \\
\hline 202 & 20.27 & Dorte & Dan & \\
\hline 203 & 20.28 & Dan & Three times two & \\
\hline 204 & 20.32 & Dirk & Can we do eh eh can we do it like I did it earlier. & \\
\hline 205 & & & Ehm Eh. Six plus six is twelve. And then must sex & \\
\hline 206 & & & times six be twelve. & \\
\hline 207 & 20.45 & Stud & No & Dorte \\
\hline 208 & 20.46 & Dorte & No. It is not that simple. We we we skip six right & counts \\
\hline 209 & & & now & each \\
\hline 210 & & Stud & [Six times six is thirty-six] & pencil \\
\hline 211 & 20.47 & Dorte & Do you now what? Now you are doing something & while \\
\hline 212 & & & that is called to preventive measure. But this is to & pointing \\
\hline 213 & & & take it too far. If we have three pencils in each hand & at them. \\
\hline 214 & & & then we have three pencils two times. Are you & \\
\hline 215 & & & agreeing that there will be six when you look at it? & \\
\hline 216 & 21.05 & Stud & No & \\
\hline 217 & 21.07 & Dorte & Yes, but it will be. One two three & \\
\hline 218 & 21.10 & Elev & No no but if you take times & \\
\hline 219 & 21.11 & Dorte & Four five six. Three. To times. & \\
\hline 220 & 21.13 & Stud & Not if you take times & \\
\hline 221 & 21.13 & Stud & No & \\
\hline 222 & 21.13 & Stud & Not if you take times then it will be nine. & \\
\hline 223 & 21.15 & Dorte & No. If you have three pencils two times. Try to count. & \\
\hline 224 & 21.18 & Stud & Oh yes. Then it is six & \\
\hline
\end{tabular}


Dorthe shows the students three pencils in each hand and she asks if anyone has a suggestion for a multiplication task (187). Diana suggests the answer, the total number (192), while Denis use addition (196). Dorte asks Denis what it will be like a multiplication task. Denis suggest three times three (199). Dorte tries to help by saying "three times" and then she shows her hands (200). Dan responds correct three times two (203). Another student interrupts now. This student wondering if you can transfer six plus six to six times six (204-206); such as "we did earlier" (204). He refers to the example where they used two plus two and related it to two times two. Another student interferes and say that six times six is thirty-six (210). Dorte now returns to the example with the pencils and ask if the students agree that there are six pencils (214-215). One of the students do not agree (216), and while Dorthe trying to explain why another students say "no, not if you take times" (220) and explains that if one takes times the answer will be nine (222). This student knows the answer of $3 \times 3$ but his knowledge of multiplication is not related to the situation. He focuses on the pencils in each hand and multiplying these numbers. Dorte then holds up the six pencils in front of the student, and asks him to count the pencils (223). If you count the pencils you will arrive at six pencils (224). Dorte choose to focus on the sum of pencils, six, as a counter-argument to three times three. However she does not explain how one arrives to three times two as a multiplication task related to the situation with the pencils. The linguistic mediation related to the tools used causes that several students interpret the situation differently than teacher does. The tension in this discussion is that several of the students perceive the quantity as referent preserving (Schwartz, 1988), by focusing only on the pencils and the total quantity of the pencils. In contrast, the teacher (Dorte) focus on different quantities, hands and pencils. The students have earlier experiences of adding pencils by combine groups of pencils and a problem arise with this new level of abstraction when multiplication involves a one to many correspondence (Clark \& Kamii, 1996); one hand and three pencils.

Meaning is culturally determined. The tools used in teaching must be accurately interpreted. However, research findings have highlighted the fact that the introduction of tools into didactic practice does not, by itself, improve teaching-learning processes. It has been shown that such improvement, when realized, does not depend on the use of the tool itself, but on the transformation that the whole learning environment has to undergo with the introduction of tools (Arzarello, Robutti \& Bazzini, 2005). Dorte wants her students to suggest a multiplication task related to the situation with the pencils. Some students suggest "three times three". This can be described as a tension between the pencils and the symbol use. The students create a different meaning in the relationship between the sign and the tool than Dorte's teaching. In other words, multiple interpretations of the example with the pencils prevent a shared understanding between Dorte and her students. This probably leads to the students' failure to appropriate the situation since they do not learn to master the mediating tool within the framework that Säljö (2005) calls "institutionalised rendering practices". The students have a common understanding with Dorte regarding the six pencils in total, but they do not comprehend this case's relationship with multiplication. The pencils as tools lead to tension in this situation.

\section{Discussion}

The research question guiding the article was: What are the tensions in the transition from additive to multiplicative reasoning in primary school classroom context? We found two main categories of tensions. One is about the solution strategies, or different expectations about the solution strategies, often between the teacher and student that arise when the students solutions are based on addition or repeated addition that are different from the teacher's expectation. Another tension is the use of tools, and the challenge in how the tools used in the classroom are too close to the students' previous experiences with similar tools used in addition, which leads the students' attention away from the multiplicative problem. Both categories of tensions could be considered as problems that arise because of the absence of a shared understanding of the situation between the teacher and his/her 
students.

The aim of this paper is at contributing to the research and conceptualisations of students' development from additive to multiplicative reasoning in primary school classroom context when students start to work with multiplication for the first time. From the results, we have seen some of the difficulties students face in the classroom when they balance between additive and multiplicative reasoning in the introduction of multiplication. There seems to be a pedagogical dilemma in the literature concerning students' understandings of models for multiplication and recommendations for teaching. On the one hand, there is consensus on the equal groups model as one of the most accessible models for young students. In the initial learning of multiplication, repeated addition is an intermediate stage (Sherin \& Fuson, 2005; Mulligan and Mitchelmore, 1997), and regarded as a natural way to introduce students to multiplication (Fischbein et al., 1985). On the other hand, the introduction and extensive use of the equal groups model is reported to reduce multiplication to repeated addition, which is not supporting multiplicative reasoning (English \& Halford, 1995). The perception of multiplication as always reducible to repeated addition has proved to be rigidly rooted and causing problems when the factors are not natural numbers (Greer, 1992). According to Larsson (2016), students who are left with this constrained conception of multiplication need more specific instruction to widen their perception of multiplication. Greer (1992) and Larsson (2016) found that repeated addition caused problems when the factors were not natural numbers.

One of the difficulties is that students struggle between additive and multiplicative reasoning already in the introduction of multiplication. The students largely used addition or repeated addition when they explained how they solved multiplicative tasks, and in these discussions about the solution strategies, it was apparent that the teachers often struggled when they tried to guide the students reasoning towards multiplication. According to English \& Halford (1995) this is because repeated addition is used both as a representation of the problem situation as well as a corresponding mathematical model. Excerpt 1 illustrates another problem in the transition between repeated addition and multiplication that supplies the literature reviewed. We expect students to move from counting all objects, to repeated addition to multiplicative calculations (Sherin \& Fuson, 2005). On the other hand, there were several episodes when the direction in the discussion went from repeated addition as a solution strategy to addition as a solution strategy.

The discussion in the literature tends to focus on if repeated addition cause problems or not in multiplication, but there seems to be a lack of focus on the tools used to illustrate multiplication. In the Norwegian context, there is a strong focus on use of tools especially in the early years in school. When teachers introduce multiplication, they use tools the students are familiar with from addition and subtraction. In several cases from the data material, tensions emerged when the teachers and students used tools to exemplify the multiplicatice task, because the students did not manage to focus on the difference between the quantities involved.

Contextually, according to a sociocultural perspective, students reasoning about multiplication cannot be separated from their participation in an interactive constitution of "taken -as-shared" mathematical meanings. An extremely important role in the development of such microculture is played by the teacher (Verschaffel et al., 2007). One of the teachers role is to orchestrate a mathematical classroom as a place where students carry out, discuss and justify solution procedures for mathematical situations (Streitlien, 2009), in which students' ideas and contribution serve as the departure pint of a whole-class discourse. Balancing content and students' participation in the mathematics classroom is complicated. According to Ryve, Larsson \& Nilsson (2013, p. 102) "there are still many complicated relations between students' engagement in the classroom, the teacher's way of orchestrating whole-class interaction, and how content is made explicit in the interaction." From the data material, there are several examples of the balancing between content and participation. 
Especially in excerpt one where the students' participation are at the expense of content, when the students begins to use different sub-totalts for addition, instead of using multiplication strategies. The teacher keeps on accepting the solutions procedures as she lets the students participate in the discussion, and misses the content in the lack of justifying the students' solution suggestion. Therefore, teachers should pay more explicit attention to differences in mathematical structure in order to prevent that students base their solution strategies on superficial associations. The students' participation largely determines the co-construction of the mathematical content and in this case leads to a "down-grading of the mathematical complexity (Emanuelsson \& Sahlström, 2008, p. 212). This study contributes to the discussion about content and participation in a Nordic perspective, by pointing at another difficulty in balancing between content and participation. We can see how the students drift from one mathematical idea (multiplication) to another idea (addition) and how this cause problems in the classroom discussions.

One interesting aspect of this study is that the teachers did not explicit focus on the differences between addition and multiplication reasoning except in the discussions of the solution strategies. Explanations like "multiplication are faster than repeated addition," "if you do not know how to multiply you can add," are used by the teachers. A conjecture based on this study is that students' tensions in the transition from additive to multiplicative reasoning are based on the lack of focusing on the fundamental differences between addition and multiplication. Future research should examine how students' manage to appropriate multiplicative reasoning by focusing on these fundamental differences.

\section{References}

Alvesson, M., \& Sköldberg, K. (2009). Reflexive methodology : new vistas for qualitative research. London: Sage.

Arzarello, F., Robutti, O., \& Bazzini, L. (2005). Acting Is Learning: Focus on the Construction of Mathematical Concepts. Cambridge Journal of Education, 35(1), 55-67.

Bryman, A. (2012). Social research methods (4th ed.). Oxford: Oxford University Press.

Carr, W., \& Kemmis, S. (1986). Becoming Critical:Education, Knowledge and Action Research. London: London, GBR: Falmer Press, Limited UK.

Clark, F. B., \& Kamii, C. (1996). Identification of multiplicative thinking in children in grades 1-5. Journal for Research in Mathematics Education, 27 (1), 41-51. doi: 10.2307/749196

Emanuelsson, J., \& Sahlström, F. (2008). The price of participation ; teacher control versus student participation in classroom interaction. Scandinavian Journal of Educational Research, 52, 205-223.

English, L. D., \& Halford, G. S. (1995). Mathematics education : models and processes. Mahwah, N.J: Lawrence Erlbaum Associates

Fernández, C., Llinares, S., Van Dooren, W., De Bock, D., \& Verschaffel, L. (2012). The development of students' use of additive and proportional methods along primary and secondary school. European journal of psychology of education, 27(3), 421438. doi:10.1007/s10212-011-0087-0

Fischbein, E., Deir, M., Nello, M. \& Marino, M. (1985). The Role of Implicit Models in Solving Verbal Problems in Multiplication and Division. Journal for Research in Mathematics Education, 16(1), 3-17.

Greer, B. (1992). Multiplication and division as models of situations. In D. Grouws (Ed.), Handbook of Research on Mathematics Teaching and Learning (pp. 276 - 295). Charlotte: Charlotte, NC, USA: Information Age Publishing.

Kaufmann, O. T. (2010). The students' first encounter with multiplication : a sociocultural approach to appropriation of multiplication in the classroom. University of Agder, Kristiansand.

Knoblauch, H. (2005). Focused Ethnography. Forum Qualitative Sozialforschung/Forum: Qualitative Social Research, 6(3). Retrieved from http://www.qualitative-research.net/index.php/fqs/article/view/20/43

Knoblauch H. 2006. Videography. Focused Ethnography and Video Analysis. In Video-Analysis. Methodology and Methods, edited by Knoblauch H., Schnettler B., Raab J., Soeffner H.-G., 69-84. Frankfurt: Peter Lang.

Larsson, K. (2016). Finding Erik and Alva: uncovering students who reason additively when multiplying. Nordisk Matematikkdidaktikk, 21(2), 69-88.

Lesh, R., \& Sriraman, B. (2010). Re-conceptualizing Mathematics Education as a Design Science. In B. Sriraman \& L. D. English (Eds.), Advances in mathematics education (pp. 123-146). Berlin: Springer.

Lo, J.-J., Grant, T., \& Flowers, J. (2008). Challenges in deepening prospective teachers' understanding of multiplication through justification. Journal of Mathematics Teacher Education, 11(1), 5-22. doi:10.1007/s10857-007-9056-6

Ludvigsen, S., Nortvedt, G. A., Pettersen, A., Pettersson, A., Sollerman, S., Ólafsson, R. F., . . Braeken, J. (2016). Northern Lights on PISA and TALIS. Copenhagen: Nordisk Ministerråd.

Moschkovich, J. N. (2004). Appropriating Mathematical Practices: A Case Study of Learning to Use and Explore Functions Through Interaction with a Tutor. Educational Studies in Mathematics, 55(1-3), 49-80. 
Mulligan, J. (1992). Children's Solutions to Multiplication and Division Word Problems: A Longitudinal Study. Mathematics Education Research Journal, 4(1), 24-41.

Mulligan, J., \& Mitchelmore, M. (1997). Young Children's Intuitive Models of Multiplication and Division. Journal for Research in Mathematics Education, 28(3), 309-330.

Rogoff, B. (1990). Apprenticeship in thinking : cognitive development in social context. New York: Oxford University Press.

Ryve, A., Larsson, M., \& Nilsson, P. (2013). Analyzing Content and Participation in Classroom Discourse: Dimensions of

Variation, Mediating Tools, and Conceptual Accountability. Scandinavian Journal of Educational Research, 57(1), 101-114. doi: 10.1080/00313831.2011.628689

Schwartz, J. (1988). Intensive quantity and referent transforming arithmetic operations. In J. Hiebert \& M. Behr (Eds.), Number concepts and operations in the middle grades (pp. 41-52). Hillsdale, N.J.:Lawrence Erlbaum Associates.

Sherin, B., \& Fuson, K. (2005). Multiplication Strategies and the Appropriation of Computational Resources. Journal for Research in Mathematics Education, 36(4), 347-395.

Streitlien, Å. (2009). Hvem får ordet og hvem har svaret? : om elevmedvirkning i matematikkundervisningen. Oslo: Universitetsforlaget. Säljö, R. (2005). Lärande och kulturella redskap : om lärprocesser och det kollektiva minnet. Stockholm: Norstedts akademiska förlag.

Tzur, R., Johnson, H. L., McClintock, E., Kenney, R. H., Xin, Y. P., Si, L., . . Jin, X. (2013). Distinguishing Schemes and Tasks in Children's Development of Multiplicative Reasoning. PNA, 7(3), 85-101.

Van Dooren, W., De Bock, D. \& Verschaffel, L. (2010). From addition to multiplication... and back: The development of students' additive and multiplicative reasoning skills. Cognition and Instruction, 28(3), 360-381. doi: 10.1080/07370008.2010.488306

Verschaffel, L., Greer, B., \& DeCorte, E. (2007). Second handbook of research on mathematics teaching and learning. In F. K. Lester (Ed.), Whole number concepts and operations (Vol. 1, pp. 557 - 628). Charlotte, N.C: Information Age.

Vygotsky, L. S. (1978). Mind in society : the development of higher psychological processes. Cambridge, Mass: Harvard University Press.

Wertsch, J. V. (1998). Mind as action. New York: Oxford University Press. 